\title{
Is Inflation All Due to Money?
}

\author{
ALBERT E. BURGER
}

NFLATION is an all-pervasive problem which affects everyone's decisions. Individuals must consider the outlook for prices when planning budgets or wage demands, when deciding whether to buy a house or in what form to hold savings, as well as a multitude of other economic decisions. Also, business is increasingly concerned about the outlook for inflation, especially as it relates to planning and capital investment. ${ }^{1}$ It is not surprising, therefore, that persistent inflation has led to increased public demands that something be done to correct the problem.

The current Administration has responded to these demands by announcing an anti-inflation program which includes, among other aspects, a promise to intervene in individual price and wage decisions in an attempt to reduce inflationary pressures. But such an approach, at best, has only a very limited chance for success because it fails to distinguish between two key characteristics of the inflation process. First, there are increases (or decreases) in prices which result from nonmonetary factors that cover a gamut of influences such as the effects of weather on agriculture and actions of foreign oil producers. The basic characteristic of all these nommonetary factors is that they have a transitory influence on inflation. They have their impact on the level of prices in selected periods, but their influence is either reversed in following periods or ceases to be a cause of period-after-period changes in prices in the same direction. It is the second aspect of inflation, the trend or persistent yearafter-year increase of prices, that is really "public enemy number one." This is the aspect of inflation to which corrective economic policy must be directed. Otherwise, all other economic programs to stop inflation will end in frustration.

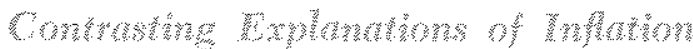

The rate of change of prices can show considerable short-term fluctuation. For example, the implicit price deflator for gross national product rose at a 5 percent

\footnotetext{
Tohn A. Tatom and James E. Turley, "Inflation and Taxes: Disincentives for Capital Formation," this Review (January 1978), pp, 2-8.
}

rate in the third and fourth quarters of 1977 , accelerated to about a 7 percent rate in the first quarter of 1978, rose further to an 11 percent rate in the second quarter, only to recede back to a 7 percent rate in the third quarter of 1978.

In addition to this variation in the general price index, there are also frequent fluctuations in the prices of individual items included in the general price indexes. Since pronounced swings in the prices of specific goods or services sometimes coincide with fuctuations in the general index of prices, specific items are frequently cited as the cause of the current inflation. Also, because the magnitude and timing of price changes vary from item to item, the blame for inflation is often transferred, from period-to-period, from one item to another. Consequently, a number of explanations of the inflation process have been offered, involving at various times the behavior of such diverse items as steel prices, exchange rate movements, union wage demands, agricultural conditions, changes in minimum wages and even the behavior of the periodically elusive anchovy. Such an analysis provides an ever-changing array of inflation villains. The blame for inflation is shifted from Arabs to coffee producers to beef producers to steel producers to specific union leaders to large banks and so on.

Concentration on such short-term oscillations in the various elements of price indexes clouds the issue of the fundamental force behind the persistent increase in the general level of prices. The problem of inflation is much more than an unfortunate sequence of increases in the prices of particular items. Focusing attention on movements in the price of particular items or each wiggle in the general price indexes gives only a description of where and when the general inflationary pressures fall in the economy. The important issue is why prices, on average, continue to rise over an extended period of time.

An explanation of the fundamental source of a continued pressure on prices requires a broader, longerrun perspective that incorporates monetary developments. When the money stock grows too rapidly relative to the rate of increase of goods and services, 
individuals find themselves holding more money than they demand, given existing income, prices, and yields (including interest rates) on other assets. In the process by which they attempt to pull their holdings of money in line with the quantity demanded, inflation results. To put the matter more simply, when "too much money is chasing too few goods" there will be persistent increases in prices. Consequently, analysis of persistent increases in the general level of prices requires consideration of the growth of the money stock. Such a monetary view contends that although prices can periodically rise or fall sharply due to nonmonetary factors, inflation continues only if these nonmonetary factors recur in succeeding periods, or if there is a continued excessive expansion of money.

The emphasis which is placed on the role of monetary actions in the fight against inflation depends very much on which of these two aspects of price changes is the center of attention. Concentration on movements in individual prices or short-term movements in the general price indexes typically leads to assignment of a limited role to monetary actions, a focus of attention on nonmonetary factors, and the recommendation of some form of direct controls on the prices of specific items. In contrast, consideration of why prices continue to increase period after period, pinpoints the rate of monetary expansion as the prime factor in the fight against inflation.

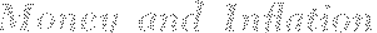

To illustrate the difference between inflation caused by monetary factors and short-term movements in price indexes caused by nonmonetary factors, consider the following simple monetary guide to inflation: ${ }^{2}$

The rate of change of prices over the next year is equal to the average rate of growth of the money stock over the previous five years.

The results of using this shorthand representation of the driving force behind the inflation process and its long-run character are presented in Table I. ${ }^{3}$ The information in this table shows that, over the period 1953-71, past or trend growth rates of money were a reasonably good guide to the year-to-year behavior of prices. During this nineteen-year period, the

For other examples of the use of monetary guides to inflation, see Richard T. Sellen, "Infation; Are We Winning the Fight?" Morgan Guaranty Survey (October 1977), pp. $7+13$, and Allan Meltzer, "It Takes Long-Range Planning to Lick Inflation," Fortune (December 1977), pp. 96-106.

3 Annual data are calculated as to the average of the four quarters of data in a given year. For example, the growth rate of prices from 1976 to 1977 on an annual basis is computed by comparing the average of the four quarters in 1977 to the average of the four quarters in 1976.

\begin{tabular}{|c|c|c|c|c|}
\hline $\mathrm{Mon}$ & $\begin{array}{l}\text { ary Growth } \\
\text { Growll Rate } \\
\text { of noney }\end{array}$ & $\begin{array}{l}\text { as an } \\
4 \\
4 \\
\text { Penlod }\end{array}$ & $\begin{array}{l}\text { helicalor of l } \\
\text { Growh Rert } \\
\text { of Prices }\end{array}$ & $(1), 12)$ \\
\hline 194752 & $23 \%$ & 195 & $15 \%$ & 08 \\
\hline $1048-53$ & 27 & 1054 & 14 & 13 \\
\hline 196954 & 32 & 1955 & 22 & 10 \\
\hline 1050,55 & 3.3 & 1056 & 31 & 02 \\
\hline 195156 & 27 & 1957 & 34 & 0.7 \\
\hline 1952,57 & 18 & 9958 & 16 & 0.2 \\
\hline 1953,58 & 15 & 1959 & 22 & 07 \\
\hline $1954-59$ & 20 & 1960 & 11 & 03 \\
\hline 195506 & 1,3 & 1961 & 09 & 0,4 \\
\hline 195661 & 15 & 1962 & 18 & o3 \\
\hline 195787 & 18 & 1963 & 15 & 0.3 \\
\hline 195863 & 22 & 1964 & 18 & 0.6 \\
\hline 195964 & 2, & 1965 & 22 & 00 \\
\hline $1900-65$ & 3.1 & 1966 & 33 & 0,2 \\
\hline 196166 & 3.6 & 1967 & 20 & 07 \\
\hline 196267 & 10 & 1968 & 45 & -0.5 \\
\hline 196368 & 48 & 1069 & 50 & 02 \\
\hline 196489 & 52 & 1970 & 5.4 & -0, \\
\hline $1965>0$ & 5 & 1071 & 3 & 0.0 \\
\hline 196671 & 5.5 & 1972 & 11 & 14 \\
\hline $1967>2$ & 6.1 & 1973 & 38 & 0.3 \\
\hline 196873 & 62 & 1974 & 97 & 3.5 \\
\hline 1969,14 & 81 & 1975 & 86 & 3,5 \\
\hline $1970-7$ & 62 & 1976 & 52 & 10 \\
\hline 197176 & 6.0 & 1977 & 52 & 01 \\
\hline
\end{tabular}

average difference between actual yearly inflation and that indicated by the past rate of monetary expansion was only 0.2 percentage point, and in twothirds of the years the error was 0.5 percentage point or less. On a quarter-to-quarter basis, the rate of change of prices oscillated around the trend rate of inflation. However, the rate of change of prices returned consistently to that dictated by the rate of monetary expansion.

Also during this period, changes in the five-year trend growth of money accurately indicated changes in the year-to-year rate of inflation. As the trend growth of money slowed in the period 1958-63, inflation was reduced. Over the next eight years, the trend growth of money accelerated steadily from less than a 2 percent rate to a 5 percent rate, and inflation rose from less than 2 percent to 5 percent per year.

In contrast to the 1953-71 period, the last six years present some examples of abnormally large differences 
between changes in the price index and the inflation indicated by past growth rates of money. In particular, 1972 and 1974-75 stand out as glaring exceptions to the previous performance of the monetary guide to inflation. To understand the behavior of inflation since 1971 , and how this experience fits into the general monetary explanation of inflation, it is crucial that one clearly understand the effect of nonmonetary factors on the behavior of prices. Specifically, it is very important to realize that, although the level of prices can change, sometimes even for a prolonged period, the rate of change of prices cannot continue to substantially deviate from the rate of monetary expansion. ${ }^{*}$

What special nonmonetary factors in 1972 and 1974-75 operated to cause such large deviations of actual changes in prices from those indicated by past growth rates of money? First, 1972 was a year of price controls. By law, reported prices were not allowed to fully reflect market pressures, especially those pushing prices upward. Under such circumstances, the reported change in prices would be expected to be considerably less than inflation indicated by a monetary guide. From the perspective of a monetary interpretation of inflation, the gap in 1972 between price changes consistent with past money growth (about $\mathbf{5 . 5}$ percent) and those reported during wage and price controls (about 4 percent) indicates (1) an upsurge of prices when price controls were removed, and (2) an incentive for transactions to take place at prices above posted prices.

Other major differences between reported changes in prices and those indicated by past monetary expansion occur in the more recent period of 1974-75. Over this period, the level of prices was sharply and unexpectedly raised by the now well-known pricing actions of the major oil-producing nations and the nonmonetary effects of weather on agriculture. The actions of the Organization of Petroleum Exporting Countries (OPEC) resulted in a substantial, unexpected rise in the price of energy. Since energy is a basic input into most production processes, these

4 Even here, however, monetary factors still play a role, although indirectly. Autonomous events can have an effect on the demand for money, which, if not matched by a one-time change in the money supply, result in a one-time increase in the level of prices. In such instances, prices rise not because of an excessive increase in the money supply but because of excessive money balances created by a decrease in money derinand.

5For a more complete technical discussion of the effects of special developments in 1972-74, see Denis S. Karnosky, "The Link Between Money and Prices-1971-76," this Review (June 1976), pp. 17-23.

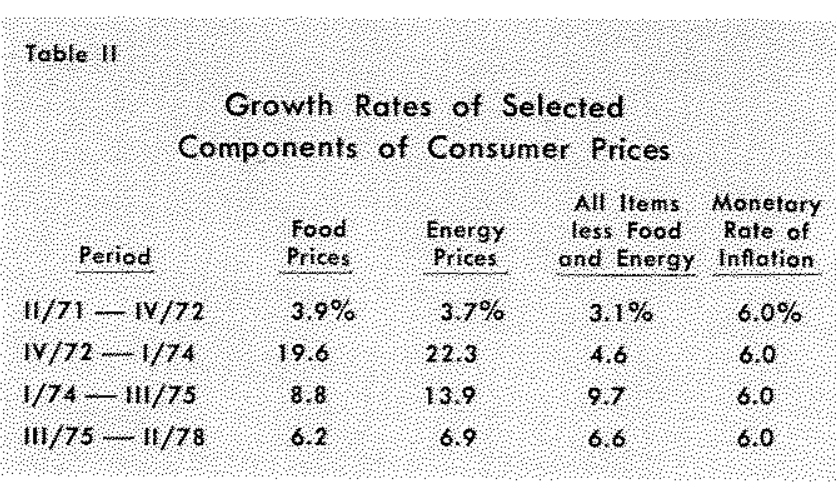

OPEC actions had a widespread, and unexpected upward effect on costs of production. There was a decrease in the effective productive capacity of the economy. With aggregate demand affected to only a minor extent and real output reduced, the level of prices rose sharply. ${ }^{6}$ Consequently, the rate of change of prices, computed over the period when these sharp upward adjustments in the level of prices took place, would be expected to be substantially, but temporarily, higher than that indicated by past monetary expansion. As their effect was absorbed in the economy, however, the rate of change of prices fell back to that dictated by the trend rate of money growth. Although in 1976-77 inflation returned to the rate dictated by monetary expansion, the level of prices remained about 4 percent higher, reflecting the effect of the OPEC actions.

Table II shows the movement of prices of selected groups of items during the period from mid-1971 to mid-1978. As shown in the table, price increases of all items other than food and energy were held to about a 3-4 percent rate while general price controls were in effect (August 1971 through April 1974). After controls were removed from most items, prices accelerated to about a 10 percent rate, as shown in the period I/74 - III/75. Table II also clearly shows that the sharp surge in prices from late 1973 into late 1975 was initially led by the sharp rise in agricultural and energy pricesi and then was reinforced by the adjustment of prices of all other items resulting from the removal of price controls in early 1974. None of these components of consumer prices

6For a technical discussion of the effect of the rise in energy prices, see Kamosky, "The Link Between Money and Prices - 1971-76" pp. 17-23; Robert H. Rasche and John A. Tatom, "The Effects of the New Energy Regime and Economic Capacity, Production, and Prices," this Review (May 1977), pp. 2-12; and "Energy Resomrces and potential GNP," this Re. view (June 1977), pp. 10-24.

TPrice controls on agricultural products were removed in September 1973. The inital OPEC rise in oil prices came in late 1973. 
(food, energy, all other) continued the sustained double digit rate of increase. Since 1975 the average rate of increase of all these prices has fallen back into line with the sustainable rate indicated by the past rates of monetary expansion.

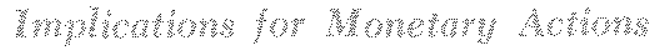

The above discussion has important implications for assessing the effects of past, current, and prospective monetary actions in the battle against inflation. The experience of the last six years makes it clear that it can be just as misleading to ascribe each and every reported increase in prices entirely to monetary factors as it is to ignore the effect of money on inflation. Consequently, failure to separate the monetary (trend) and nonmonetary (transitory) aspects of inflation can lead to confused demands on policymakers.

To illustrate the importance of this distinction, consider economic developments over the last six years. During the three-year period ended in the second quarter of 1971 , the persistent rate of inflation was very much in line with the rate indicated by a monetary guide to inflation. Over the next six quarters, however, prices rose at about a 4 percent rate. Could this fall in inflation be attributed to monetary actions? The answer is no, the fall in reported inflation was strictly due to nonmonetary factors, that is, price controls that went into effect in August 1971.

From early 1973 through early 1975 prices rose very rapidly. From a 4 percent rate, inflation accelerated to about an 8 percent rate in the year ended first quarter 1974. Then, over the next four quarters inflation took another sharp leap upward, averaging 11.6 percent. If one attributes all of these increases in prices during this period to the cumulative effect of past monetary actions, then it appears that the Federal Reserve had let things get seriously out of hand. On the other hand, if the short-run influences of nonmonetary developments on prices are taken into consideration, quite a different conclusion emerges. Careful analysis of the effects on prices of weather, OPEC actions, and the removal of price controls would indicate a sharp rise in the level of prices beginning in late 1973 that was not the result of past monetary actions. The basic rate of inflation, the one determined by the cumulative effect of past monetary actions, remained at about 6 percent.

Early in 1975, inflation dropped sharply, and averaged 6.5 percent over the remainder of the year.
Then inflation eased further to a 4.4 percent rate over the first three quarters of 1976. Was this substantial slowing in inflation the result of monetary policy actions? Again the answer is no. The slowing in the rate of change of prices from the double-digit pace of 1974 reflected only that the OPEC actions of late 1973 were not repeated in the following years, the general adjustment of other prices to the removal of price controls had been completed, and favorable agricultural conditions resulted in a sharp drop in the rate of increase of food prices. Did the basic inflation slow to a sustained 4.5 percent rate by late 1976 ? Again the answer is no. From late 1976 to the end of 1977 inflation returned to a 6 percent rate, the same as that indicated by the trend growth of money.

What was the effect of monetary actions, as measured by the growth of the money stock, on inflation over the six-year period 1972-77? In particular, what was the effect of allowing M1 to grow at about an 8 percent rate from late 1971 to early 1973, then cutting M1 growth to 6 percent for a year, further slashing it to 4 percent for a year, and then progressively reaccelerating $\mathrm{M} 1$ growth, first to 5 percent for six quarters, and then to almost 8 percent over the two-year period ended in the third quarter of 1978? Did these gyrations in money growth substantially change the basic rate of inflation? Using the past growth pattern of $\mathrm{MI}$ as a guide to inflation, then again the answer is no. Money had grown at a 6 percent rate over the five years (20 quarters) ended in the fourth quarter of 1971, remained at 6 percent in the 20 quarters ended in early 1975 and by the end of the fourth quarter of 1977 the twentyquarter growth rate of $\mathrm{M} 1$ was still essentially 6 percent.

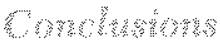

In analyzing the inflationary process, one must be careful to avoid shortsightedness. In particular, shortrun gyrations in prices must be distinguished from persistent changes in prices. Monetary policy cannot prevent the quarter-to-quarter fluctuations in the price level that naturally result from the dynamics of economic activity. However, concentrating on only these short-run fluctuations in the level of prices can result in falsely blaming nonmonetary factors for a persistent rise in prices. The analysis of inflation then tends to bounce, month-to-month, quarter-to-quarter from one item or sector of the economy to another. Such an approach diverts attention from the role of monetary actions, results in failure to permanently reduce inflation and ultimately means that inflation will return 
to plague the economy. The monetary actions of the government must be given a key position in any program to permanently reduce persistent inflation.

Over the first half of 1978 , prices rose at about a 9 percent rate. Should inflation be expected to continue at this rate? The monetary guide presented in this paper, indicates a persistent inflation of about 6.2 percent for the period III/78 - III/79. Some economists would contend that individuals now adapt their expectations of inflation more rapidly than previously, hence, a five-year trend rate of growth for $\mathrm{Ml}$ is too long. If the period for calculating the trend rate of money is shortened to four years, the inflation indim cated for III/78 - III/79 rises to 6.4 percent. Shortening the period further to three years, raises the basic inflation rate to 6.8 percent for the next year. Consequently, the lasting rate of inflation indicated by past monetary developments falls in a fairly narrow range of 6.2 .7 percent, nowhere near a 9 percent rate.

However, just because a rough monetary guide to inflation, such as the one presented in this article, does not indicate that past monetary actions have yet cumulated into a 9 percent persistent inflation should not be taken as a cause for rejoicing. A persistent inflation of 6.5-7 percent is still at least three times as fast as any lasting inflation the U.S. economy experienced from the end of World War II through 1965. Furthermore, historical evidence indicates that the development of such a persistent inflation is a rather sluggish process that does not adjust immediately to accelerations or decelerations of the growth of money. ${ }^{8}$

Currently, the trend rate of money growth is being held down by the 5 percent growth rate that prevailed from the third quarter of 1973 to the third quarter of 1976. In sharp contrast, over the last two years (III/76 - III/78), the average rate of monetary expansion accelerated to 8 percent. As the effect of the 5 percent growth wears off, if money continues to grow at an 8 percent or faster rate, inflation will rise sharply to a persistent, year-after-year, 8-9 percent rate.

8For example, growth of money (M1) accelerated to about a 7 percent annual rate in 1968 , after rising at an average rate of about 4 percent over the previous five years. Inflation did not rise to 7 percent in 1968 , instead it was 4.5 percent, about in line with the 4 percent average growth of $M 1$ over the previous five years. However, as the money stock continued to grow rapidly by past standards - at a 6 percent rate in 1969 - the five year average growth of Ml rose to 5.2 percent by the end of 1969 and the rate of intlation moved up to 5.4 percent in 1970. This increase in inflation took place even though the growth of M1 subsequently decreased to about a 4 percent rate in 1970 . 